\title{
UNIVERSITYOF
}

FORWARD

THINKING

WESTMINSTER用

WestminsterResearch

http://www.westminster.ac.uk/westminsterresearch

\section{Synthesis of graft copolymers based on hyaluronan and poly(3- hydroxyalkanoates)}

Huerta-Angeles, G., Brandejsová, M., Nigmatullin, N., Kopecká, K., Vágnerová, H., Šmejkalová, D., Roy, I. and Velebný, V.

NOTICE: this is the authors' version of a work that was accepted for publication in Carbohydrate Polymers. Changes resulting from the publishing process, such as peer review, editing, corrections, structural formatting, and other quality control mechanisms may not be reflected in this document. Changes may have been made to this work since it was submitted for publication. A definitive version was subsequently published in Carbohydrate Polymers, DOI: 10.1016/j.carbpol.2017.05.011, 2017.

The final definitive version in Carbohydrate Polymers is available online at:

https://dx.doi.org/10.1016/j.carbpol.2017.05.011

(C) 2017. This manuscript version is made available under the CC-BY-NC-ND 4.0 license http://creativecommons.org/licenses/by-nc-nd/4.0/

The WestminsterResearch online digital archive at the University of Westminster aims to make the research output of the University available to a wider audience. Copyright and Moral Rights remain with the authors and/or copyright owners.

Whilst further distribution of specific materials from within this archive is forbidden, you may freely distribute the URL of WestminsterResearch: ((http://westminsterresearch.wmin.ac.uk/)).

In case of abuse or copyright appearing without permission e-mail repository@westminster.ac.uk 


\section{Accepted Manuscript}

Title: Synthesis of graft copolymers based on hyaluronan and poly(3-hydroxyalkanoates)

Authors: Gloria Huerta-Angeles, Martina Brandejsová, Rinat Nigmatullin, Kateřina Kopecká, Hana Vágnerová, Daniela Šmejkalová, Ipsita Roy, Vladimír Velebný

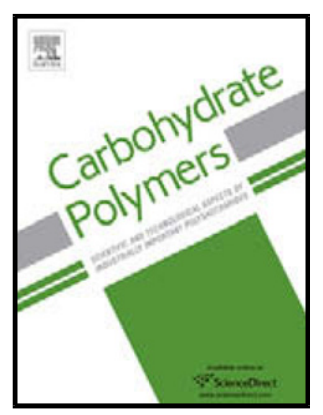

PII: S0144-8617(17)30508-8

DOI: http://dx.doi.org/doi:10.1016/j.carbpol.2017.05.011

Reference: CARP 12297

To appear in:

Received date: $\quad$ 17-2-2017

Revised date: $\quad 2-5-2017$

Accepted date: $\quad 3-5-2017$

Please cite this article as: Huerta-Angeles, Gloria., Brandejsová, Martina., Nigmatullin, Rinat., Kopecká, Kateřina., Vágnerová, Hana., Šmejkalová, Daniela., Roy, Ipsita., \& Velebný, Vladimír., Synthesis of graft copolymers based on hyaluronan and poly(3-hydroxyalkanoates).Carbohydrate Polymers http://dx.doi.org/10.1016/j.carbpol.2017.05.011

This is a PDF file of an unedited manuscript that has been accepted for publication. As a service to our customers we are providing this early version of the manuscript. The manuscript will undergo copyediting, typesetting, and review of the resulting proof before it is published in its final form. Please note that during the production process errors may be discovered which could affect the content, and all legal disclaimers that apply to the journal pertain. 


\section{Synthesis of graft copolymers based on hyaluronan and poly(3-hydroxyalkanoates)}

Gloria Huerta-Angeles, ${ }^{1 *}$ Martina Brandejsová, ${ }^{1}$ Rinat Nigmatullin, ${ }^{2, *}$ Kateřina Kopecká, ${ }^{1}$ Hana Vágnerová, ${ }^{1}$ Daniela Šmejkalová, ${ }^{1}$ Ipsita Roy ${ }^{2}$ and Vladimír Velebný. ${ }^{1}$

${ }^{1}$ Contipro a.s., Dolní Dobrouč 401, 56102 Dolní Dobrouč, Czech Republic

${ }^{2}$ Department of Life Science, Faculty of Science and Technology, University of Westminster, 115 New Cavendish Street, London W1W 6UW, United Kingdom

Corresponding author: huerta-angeles@contipro.com

${ }^{*}$ present address; The University of Exeter, Prince of Wales Road, Exeter, Devon, EX4 4SB, United Kingdom

\section{Highlights}

- Joining two natural motifs: hyaluronan (HyA) and poly(3-hydroxyalkanoates) (PHAs)

- Hydrolysis of PHAs yielded oligomers suitable for HyA covalent grafting

- 1,1, Carbonyldiimidazole allowed hyaluronan modification under mild conditions

- Water soluble copolymers as potential carriers for drug delivery

\section{Abstract}

This work reports the synthesis and characterisation of new amphiphilic hyaluronan (HA) grafted with poly(3-hydroxyalkanoates) (PHAs) conjugates. Hydrolytic depolymerisation of PHAs was used for the synthesis of defined oligo(3-hydroxyalkanoates)-containing carboxylic terminal moieties. A kinetic study of the depolymerisation was followed to prepare oligomers of required molecular weight. PHAs were coupled with hydroxyl groups of HA mediated by N, N'-carbonyldiimidazole (CDI) or HSTU Tetramethyl-O-(N-succinimidyl) uronium hexafluorophosphate. For the first time, the covalent bonding of oligo derivatives of $\mathrm{P}$ (3-hydroxybutyrate), $\mathrm{P}$ (3-hydroxyoctanoate), $\mathrm{P}$ (3-hydroxyoctanoateco-3-hydroxydecanoate) and $\quad \mathrm{P}$ (3-hydroxyoctanoate-co-3-hydroxydecanoate-co-3hydroxydodecanoate) and HA was achieved by "grafting to" strategy. Achieved grafting degree was a function of hydrophobicity of PHA, Mw and polarity of the solvent. The most suitable reaction conditions were observed for oligo (3-hydroxybutyrate) grafted to HA (grafting degree of $14 \%$ ). Graft 
copolymers were characterized by FT-IR, NMR, DSC and SEC-MALLS. Graft copolymers can be physically loaded with hydrophobic drugs and may serve as drug delivery system.

\section{Abbreviations:}

3T3-NIH: standard fibroblast cell line; CDI : 1,1'-Carbonyldiimidazole; DMAP: 4dimethylaminopyridine; DOSY: diffusion ordered spectroscopy; DSC: Differential Thermal calorimetry, Fourier transform infrared spectroscopy (FT-IR) ; HSTU: Tetramethyl-O-(N-succinimidyl)uronium hexafluorophosphate; HPLC, high-performance liquid chromatography; HSQC, heteronuclear single quantum coherence; IPA, isopropyl alcohol; MTT, 3-(4,5-dimethylthiazol-2-yl)-2,5-diphenyl tetrazolium bromide; $\mathrm{P}(3 \mathrm{HB})$ : $\mathrm{P}(3$-hydroxybutyrate), $\mathrm{P}(3 \mathrm{HO})$ : $\mathrm{P}$ (3-hydroxyoctanoate), $\mathrm{P}(3 \mathrm{HO}-3 \mathrm{HD})$ : $\mathrm{P}$ (3-hydroxyoctanoate-co-3-hydroxydecanoate), P(3HO-3HD-3HDD): P(3-hydroxyoctanoate-co-3hydroxydecanoate-co-3-hydroxydodecanoate), SEC-MALLS, size exclusion chromatography coupled to multi angle laser light scattering; TEA, triethylamine;

Keywords : Hyaluronan; ; ; ; , polyhydroxyalkanoates, esterification, graft copolymers, hydrolysis

\section{Chemical compounds studied in this article:}

Sodium hyaluronate (PubChem CID: 53447380), Curcumin (PubChem CID: 101736865), Resveratrol (PubChem CID: 445154) 


\section{Introduction}

Polymers have played an integral role in the advancement of drug delivery technology by providing controlled release of therapeutic agents in constant doses over long periods, cyclic dosage, and tunable release of both hydrophilic and hydrophobic drugs (Liechty, Kryscio, Slaughter, \& Peppas, 2010). The latest developments have specially shown that hydrophobic drugs can be physically encapsulated into polymeric micelles via hydrophobic interactions formed by amphiphilic polymers. Particularly, polymeric micelles have attracted interest in the development of drug delivery systems for cancer therapy (Chu et al., 2016).

Hyaluronan or hyaluronic acid $(\mathrm{HA})$, is a glycosaminoglycan composed of repeating disaccharide units of $\mathrm{N}$-acetyl-D-glucosamine (GIcNAc) and D-glucuronic (GIcA) linked by glycosidic bonds $\left([4)-\beta-D-G l c p A-(1 \rightarrow<\right.$ Inlinelmage $\left.1>3)-\beta-D-G l c p N A c-(1 \rightarrow<\text { Inlinelmage } 2>]_{n}\right)$, which is widely used in anticancer drug delivery due to its ubiquitous presence in the human body and thereby its biocompatibility, biodegradability, and non-toxicity. With the increasing demands of smart nanomicelles or vesicles, it is essential to modify the structure of HA, increase its stability and shelflife i.e. by grafting with synthetic aliphatic polyesters such as poly(lactic acid) (PLA) (Pravata et al., 2007), poly(lactide-co-glycolide) (PLGA) (Son et al., 2014) or poly(caprolactone) (PCL) (Chen et al., 2017). Unfortunately, these conjugates often suffer from several drawbacks due to the use of synthetic blocks, often giving problems due to the presence of unreacted monomers, catalysts, toxic degradation or side-products (Maitz, 2015).

To address these issues, biologically derived polymers created by living organisms are advantageous. Poly(3-hydroxyalkanoates) (PHAs) are excellent candidate biomaterials due to their exceptional biodegradability and biocompatibility. They comprise a family of natural (aliphatic) polyesters produced by microorganisms. However, PHAs are characterized by high crystallinity and its hydrolytic degradation requires months (Z. Li, Yang, \& Loh, 2016). PHAs need to have tunable hydrophilicity, chemical functionalities, and appropriate hydrolytic stability to expand their 
therapeutic applications towards more advanced areas (Z. Li \& Loh, 2015). Although, blending of PHAs and hydrophilic polymers have been proposed, these blends are brittle due to the incompatibility between the second polymer and the PHA matrix (Hsu, Wu, Liao, \& Cai, 2015). Water soluble PHAs also show great potential in controlled drug release, cancer therapy, DNA/siRNA delivery and tissue engineering. Previously, PHA-based water soluble polymers were prepared by i) block copolymerization with hydrophilic components such as polyethylene glycol (PEG) (J. Li et al., 2006) or Poly (N-isopropylacrylamide) (PNIPAA) (Ma, Wei, Yao, Wu, \& Chen, 2016); ii) graft copolymerization with biopolymers such as chitosan (Arslan, Hazer, \& Yoon, 2007), cellulose (Wei, McDonald, \& Stark, 2015), but also synthetic polymers: poly(ethylene imine) (PEI) (Zhou et al., 2012) or PEG (Babinot, Guigner, Renard, \& Langlois, 2012). However, the exogenous nature of the polymers is still a drop out for biomedical applications (Mitragotri et al., 2015).

Herein, we describe the synthesis of water-soluble conjugates containing PHAs and HA attached covalently by esters bonds. Partial depolymerisation of PHAs under acidic conditions was used for the preparation of oligomeric PHA derivatives-containing carboxylic moieties at the terminal end. Screening of coupling reagents for binding PHAs to HA has been conducted. The resulting conjugates were characterized by FT-IR, SEC-MALLS, and NMR and thermal analyses. We hypothesized that these materials can self-assemble in aqueous media. Therefore, the potential application of these conjugates as drug delivery carriers was explored by encapsulation of two hydrophobic drugs: curcumin and resveratrol.

\section{Materials and Methods}

\subsection{Materials}

Sodium hyaluronate (laboratory grade, $\mathrm{Mw}: 13,700 \mathrm{~g} / \mathrm{mol}$ and polydispersity of 1.5, further description is provided in supplementary part S.1.1) was provided by Contipro a.s. (Dolni Dobrouc, Czech Republic). Poly(3-hydroxybutyrate) (P(3HB) was extracted from biomass of Bacillus cereus SPV after fermentation in the Kannan and Rehacek medium with glucose $(20 \mathrm{~g} / \mathrm{L})$ as the sole carbon source 
(Basnett et al., 2013). Three medium chain length PHAs (mcl-PHAs) were used in this study, identified as the homopolymer of 3-hydroxyoctanoate ( $\mathrm{P} 3 \mathrm{HO})$, copolymer of 3-hydroxyoctanoate and 3hydroxydecanoate ( $\mathrm{P}(3 \mathrm{HO}-3 \mathrm{HD})$ ) and terpolymer of 3-hydroxyoctanoate, 3-hydroxydecanoate and 3hydroxydodecanoate ( $\mathrm{P}(3 \mathrm{HO}-3 \mathrm{HD}-3 \mathrm{HDD}))$. These medium chain length $\mathrm{PHAs}$ were produced by Pseudomonas mendocina CH50 (NCIMB 10542) as reported in a previous work (Rai et al., 2011). Tetrahydrofuran (THF, 99.5\%), isopropanol (IPA, 99.7\%), triethylamine (TEA, 98\%) and dimethyl sulfoxide (DMSO, 99.9\%) were purchased from Lach-Ner (Czech Republic). Benzoyl chloride (BC, 99\%), 2, 4, 6-trichlorobenzoyl chloride (TBC, 97\%), N, N, N', N'-Tetramethyl-O-(N-succinimidyl) uronium hexafluorophosphate (HSTU), N, N'-Carbonyldiimidazole (CDI, 97\%) and acetic acid ( $\geq 99.5 \%)$ were purchased from Sigma-Aldrich. Analytical grade CHROMASOLV ${ }^{\circledR}$ solvents were used for chromatographic analysis. Deuterium oxide $\left(D_{2} \mathrm{O}\right)$ was purchased from CortecNet (France). 4(Dimethylamino) pyridine (DMAP, 99.5\%) was purchased from Merck. 3-(4, 5-dimethylthiazol-2-yl)2,5-diphenyltetrazolium bromide (MTT) and ethidium homodimer were purchased from Life Technologies.

\subsection{Hydrolytic depolymerisation of polyhydroxyalkanoates (PHAs)}

Partial depolymerisation of PHAs was used for the preparation of oligo(3-hydroxyalkanoates). In brief, $3.0 \mathrm{~g}$ of the respective (dry) PHA was suspended in a mixture of $166 \mathrm{~mL}$ of glacial acetic acid and $34 \mathrm{~mL}$ of distilled water. Hydrolysis was carried out at $100-105^{\circ} \mathrm{C}$ under reflux for up to 30 hours. In this work, a detailed kinetics of depolymerisation was studied for $\mathrm{P}(3 \mathrm{HB})$ (supplementary part Figure S1). In this experiment, $5 \mathrm{~mL}$ aliquots were withdrawn periodically and polymer was precipitated in cold methanol and used for further characterisation. The obtained oligo(3hydroxybutyrate) shorten as oligo(3HB) was purified by washing several times with distilled water until neutral reaction of the supernatant was obtained.

\subsection{Synthesis of conjugates based on hyaluronan and PHAs}


Sodium hyaluronate ( $2 \mathrm{~g}, 5 \mathrm{mmol}$ of dimers) was dissolved overnight in distilled water ( $40 \mathrm{~mL}$ ) under stirring. After the solution was homogeneous, TEA (triethylamine, $0.7 \mathrm{~mL}, 5 \mathrm{mmol}$ ) was added, followed by $0.003 \mathrm{~g}$ of DMAP. At the same time and in a second reaction flask, the PHA was activated. The respective molar equivalents of PHA based on a monomer unit as shown in Table 1 were dissolved in $40 \mathrm{~mL}$ of DMSO, followed by the corresponding equivalents of CDI or the respective activator (Table 1) and $0.7 \mathrm{~mL}$ of TEA ( $5 \mathrm{mmol})$. The formation of the imidazolide (activation) was carried out at room temperature or $60^{\circ} \mathrm{C}\left(T_{a}\right)$ for the activation time $\left(t_{a}\right)$ described in Table 1 . Then, the solution of the corresponding activated PHA was added to the solution containing HA at temperature $\left(T_{H A}\right)$ for the time $\left(t_{\text {HA }}\right)$ resumed in Table 1 . The crude product was isolated by precipitation adding a saturated solution of sodium chloride $(5 \mathrm{~mL})$. After that the product was washed with an excess of anhydrous isopropanol $(300 \mathrm{~mL})$. The product was washed again with solutions of isopropanol: water $(85 \% \mathrm{v} / \mathrm{v}$, $4 \times 100 \mathrm{~mL}$ ). Finally, the precipitate was washed $4 \times$ with $100 \mathrm{~mL}$ of absolute isopropanol, filtered and dried in an oven for at least $24 \mathrm{~h}$. To ensure reproducibility of the reaction, each synthesis was repeated for at least three independent times. In general, the procedure is reproducible up to $15 \mathrm{~g}$ scale (data not shown). In all the cases, products with identical structural characteristics, consistent degree of grafting (GD), yield and purity were obtained. The reaction conditions used for the preparation of HA (acid and TBA form are described in supplementary section S2 and S3) and the grafting of HA in supplementary S4.

\subsection{Characterization of modified hyaluronan}

The methods used for the characterization of the modified HA as infrared spectroscopy (IR), nuclear magnetic resonance (NMR), SEC-MALLS (Size-Exclusion Chromatography Combined with Multiangle Laser Light Scattering), Gel permeation chromatography (GPC) and differential scanning calorimetry (DSC), are described in supplementary part.

\subsection{Encapsulation of hydrophobic drug}


Resveratrol or curcumin ( $\sim 5 \mathrm{mg}$ ) were dissolved in $3 \mathrm{~mL}$ of 2-propanol and mixed with aqueous solution of hyaluronan graft-oligo (3-hydroxybutyrate) (Oligo (3HB)-g-HA) or sodium oleyl hyaluronate (HA-C18:1). Solvents were removed under reduced pressure. Resulting film was rehydrated with water, filtered through a $0.1 \mu \mathrm{m}$ glass fiber to remove unincorporated compound and freeze-dried. The loaded amount of resveratrol or curcumin was quantified by HPLC.

\section{Results and discussion}

\subsection{Synthesis of oligomeric derivatives of PHAs}

The biologically-synthesized PHAs exhibit a molecular weight about 1.5 MDa. These high molecular weight, PHAs can be depolymerised (hydrolysed), to yield a PHA having a molecular weight as low as $2 \mathrm{kDa}$. In this work, depolymerisation was employed to obtain low molecular weight derivatives of PHAs. The hydrolytic cleavage of PHAs was performed using acetic acid solutions of high concentration (above $80 \%$ ) and elevated temperature $\left(110^{\circ} \mathrm{C}\right)$. Except for hydrolysis, these conditions ensured homogenous conditions for the depolymerisation facilitating predictive preparation of both low molecular weight PHA (Mw about $15 \mathrm{kDa}$ ) and oligo(3-hydroxyalkanoates) (Mw about $2 \mathrm{kDa}$ ) products. Detailed description of PHA depolymerisation, including degradation kinetics and product characterization was exemplified for $\mathrm{P}(3 \mathrm{HB})$, one of the shortest polyesters from $\mathrm{PHA}$ family. $\mathrm{P}(3 \mathrm{HB})$ depolymerisation was studied monitoring the evolution of degree of depolymerisation during the hydrolysis. As can be seen from Figure S1, $\mathrm{P}(3 \mathrm{HB})$ hydrolysis in acetic acid solution results in exponential decay of molecular weight with the time. Depolymerisation/degradation processes have been modelled as random scission of macromolecular chains for different types of polymers (Cran, Gray, Scheirs, \& Bigger, 2011; Martens et al., 2011; Staggs, 2002). Kinetic data for P(3HB) hydrolysis are reported in Figure $\mathbf{S 1}$. The random chain scission corresponded to the first-order kinetics which was presented in a term of number-average degree of polymerization by Ekenstam equation:

$$
\left(1 / \mathrm{DP}_{\mathrm{t}}-1 / \mathrm{DP}_{0}\right)=\mathrm{kt}
$$


where $\mathrm{DP}_{0}$ and $\mathrm{DP}_{\mathrm{t}}$ are the initial degree of polymerization and degree of polymerization at time $\mathrm{t}$ respectively, and $\mathrm{k}$ is the rate constant (Martens et al., 2011). The high degree of linearity of this plot demonstrates the applicability of an overall first-order kinetic analysis to this system as a good approximation. The rate constant derived from the line slope is $1.87 \times 10^{-3} \mathrm{~h}^{-1}$. The established relation between degree of depolymerisation and hydrolysis times allows for the selection of hydrolysis duration to obtain oligo(3-hydroxybutyrate) of required molecular weight starting from $\mathrm{P}(3 \mathrm{HB})$ of different initial molecular weight.

Oligo (3-hydroxybutyrate) obtained after hydrolysis for $20 \mathrm{~h}$ is completely soluble in THF or DMSO at room temperature. Solubility in these solvents is achieved when weight-average molecular weight is below $2.2 \mathrm{kDa}$, making the polymer suitable for grafting to other polymers, including HA. As it can be expected, decrease of molecular weight leads to change in thermal properties. DSC thermograms presented in Figure 1 demonstrate that glass transition and melting temperature shifted to lower temperatures with the decrease of molecular weight. Table $\mathbf{S 1}$ summarizes dependence of thermal properties on molecular weight for partially depolymerised $\mathrm{P}(3 \mathrm{HB})$. Glass transition decreased from $2.5^{\circ} \mathrm{C}$ for initial high molecular weight $\mathrm{P}(3 \mathrm{HB})(\mathrm{Mw} \sim 273.5 \mathrm{kDa})$ to $-11.1^{\circ} \mathrm{C}$ when weight average molecular weight reduced to $\sim 2.2 \mathrm{kDa}$. Even more significant decrease is observed for melting temperature. Oligo(3HB) with number-average molecular weight of $\sim 2.2 \mathrm{kDa}$ melts below $100^{\circ} \mathrm{C}$ compared with almost $174.5^{\circ} \mathrm{C}$ for initial high molecular weight $\mathrm{P}(3 \mathrm{HB})$. Interestingly, Oligo (3HB) shows a complex melting event with a relatively narrow peak at lower temperature (Figure 1). The ratio of peak area of this peak to area of a doubled peak of higher temperatures increases with the decrease of degree of polymerisation. This implies that first peak is due to a fraction of lower molecular weight which increases for more hydrolysed samples. All hydrolysed samples remain highly crystalline like the parent $\mathrm{P}(3 \mathrm{HB})$, if enthalpy of fusion is assumed as not dependent on molecular weight as observed for the $100 \%$ crystalline material (Domínguez-Díaz et al., 2015). 
$\mathrm{P}(3 \mathrm{HB})$ acidic hydrolysis allowed the formation of oligomers with terminal functionalities onto the degraded PHA polyester. In this case, hydroxyl group at one end of molecule and carboxyl group at another end (Figure 3, STEP A). ${ }^{1} \mathrm{H}$ NMR shows end-monomer units as additional peaks with small differences in chemical shifts compared with peaks of corresponding protons in main chain (Figure 2). As an example, inserts in Figure 2 show expansions for sextet of $-\mathrm{O}-\mathrm{CH}$ - at $5.2 \mathrm{ppm} .{ }^{1} \mathrm{H}$ NMR reveals end hydroxyl groups at $\delta=4.2 \mathrm{ppm}$ in oligo(3-hydroxybutyrate), which are not detectable in initial $\mathrm{P}(3 \mathrm{HB})$ due to a low content. An additional singlet at $\delta=2.0 \mathrm{ppm}$ appears in ${ }^{1} \mathrm{H}$ NMR for oligo(3HB). This is assigned as methyl protons of acetyl. Thus, a part of hydroxyl groups in oligo(3HB) is esterified with acetic acid. End group NMR analysis indicates that around $40 \%$ of hydroxyl groups of oligo (3HB) were esterified.

\subsection{Preparation of hyaluronan graft-poly(3-hydroxyalkanoates)}

At the beginning, the physical combination of HA and PHAs (blending) was tested as a part of the development of novel materials. However, the physical mixture was not possible due to poor interfacial interactions between the two polymers. Therefore, a second alternative was the chemical bonding. Different approaches were tested for the conjugation. The formation of an ester bond between a carboxylic acid moiety of PHA and hydroxyl moiety of HA is the core reaction of this work. The first step of this condensation reaction, the activation of the carboxyl moiety is the critical one. There are several methods available for activating carboxyl moieties for coupling to the hydroxyl moiety in HA, such as the generation of carboxylic halides, mixed anhydrides or the use of carbodiimides (Montalbetti \& Falque, 2005). At first, we applied the mixed anhydride methodology using benzoyl chloride as an activating agent (Huerta-Angeles et al., 2016). Although several reaction conditions involving different solvents, bases and reaction times were tested, the chemical bonding was not successful (Table 1, entries 13-15). Second, we tried to use the coupling approach. Reagents used in peptide coupling such as the phosphonium-and the uronium -(imonium-) type reagents, may be useful for carboxyl activation. In contrast to activation by carbodiimides, these compounds achieve 
high coupling rates accompanied by few undesired side reactions (El-Faham \& Albericio, 2011). Consequently, N, N, N', N'-Tetramethyl-O-(N-succinimidyl) uronium hexafluorophosphate (HSTU) was tested in this work. Although HSTU mediated the coupling between PHA and HA the reaction efficiency was lower (Table 1, entries $9, \mathbf{1 0}$ ) compared to CDI. The synthetic steps used for the preparation of the copolymers containing HA and PHAs mediated by CDI are depicted in Figure 3. CDI-coupling reaction is usually carried out in polar organic solvents (i.e. THF, formamide, DMF or DMSO), which is important because the solvent is expected to be miscible with the solvents commonly used for chemical modification of HA (or its salts). In fact, CDI was successfully used for the esterification of HA with ferulic acid in formamide (Cappelli et al., 2014). However, similar reaction conditions were not applicable for HA chemical modification with alkanoates (Table 1, entry 16). When we replaced formamide with DMSO, PHA terminal -carboxyl moiety was activated by CDI yielding imidazolide 1 (Figure 3, STEP B), which reacted in the next step with the primary hydroxyl group in aqueous-organic solvent system (water/DMSO) or DMSO, yielding esterified HA (Figure 3, STEP C). The activation can be performed as one-pot reaction. The rate of imidazolide formation was followed by NMR spectroscopy in the presence of TEA (Figure S2) in DMSO. After 4h, conversion larger than $98 \%$ of the Oligo(3HB) to the imidazolide intermediate was achieved at $25{ }^{\circ} \mathrm{C}$ (Figure S2). Also, the presence of TEA was found to accelerate the reaction (data not shown). To ensure complete consumption of the $\mathrm{CDI}$ for all types of PHAs, the reaction towards the imidazolide was carried out at $60^{\circ} \mathrm{C}$ with equimolar ratios of PHAs/CDI (Heinze, Liebert, \& Koschella, 2006). However, based on the NMR data, we found that the imidazolide unexpectedly degraded at $60^{\circ} \mathrm{C}$ and reaction sub-products also appeared i.e. a new signal was detected at $4.6 \mathrm{ppm}$ (Figures S3), which probably explains the lower degree of grafting when high temperature is used (Table 1, entries 1, 17 and 19).

In the second reaction step, the esterification of HA was studied. The esterification reaction can be carried out in water (HA sodium salt) or in an aqueous-organic solvent system (i.e. DMSO or THF). Alternatively, the esterification reaction can be performed in organic solvents, such as dimethylsulfoxide (DMSO) or dimethylformamide (DMF). In this case, the commonly used HA sodium 
salt must be converted into either its acidic form or a tetrabutylammonium (TBA) salt for solubilisation in organic solvents (see supplementary part). The results in Table 1 demonstrated that Oligo (3HB) reacts efficiently at room temperature and independently on the polarity of the reaction solvent, probably because it is the least hydrophobic of the four oligomers tested in this work (Table 1, entries, 19-22). In contrary, DMSO and high temperature $\left(60^{\circ} \mathrm{C}\right)$ was needed for the HA esterification with PHA having medium chains, including Oligo (3HO), (3HO-co-3HD) and (3HO-co-3HD-co-3HDD) copolymers (Table 1, entries 2-6 compared to entries 23-28). Therefore, the conversion of HA in its salts was necessary for the reactivity of medium chains alkanoates in organic solvent. However, it should be reminded that the conversion is always accompanied by degradation of HA backbone, which is not desirable for some applications. When HA sodium salt and DMSO/water solvent was used, an increased reactivity was found for Oligo (3HB) compared to the smaller grafting degree obtained for low molecular weight $\mathrm{P}(3 \mathrm{HB})$ probably due to limited chain mobility (Table 1, entries 11, 12, 17 and 19). Furthermore, the reaction requires at least an equimolar ratio of $\mathrm{PHA} / \mathrm{HA}$ (Table 1, entries 19-22), while lower molar ratio produces lower grafting degree (Table 1, entry 18). The highest grafting degree (14\%) was reached for Oligo (3HB) after $24 \mathrm{~h}$ of activation with CDI at room temperature, followed by $24 \mathrm{~h}$ of esterification reaction carried out in DMSO/H2O mixture at room temperature (Table 1, entry 22). 
${ }^{1} \mathrm{P} 3 \mathrm{HB} ; \mathrm{Mw}=15.3 \mathrm{kDa}$ (Table S1), ${ }^{2}$ Oligo (3HB); $\mathrm{Mw}=2.3 \mathrm{kDa}$

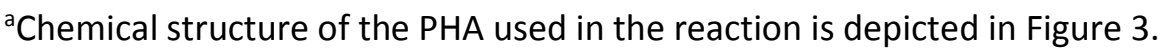

${ }^{\mathrm{b}}$ The reaction with $\mathrm{HA}(13.7 \mathrm{kDa}), 2.5 \%(\mathrm{w} / \mathrm{v})$ concentration.

${ }^{c}$ The activation is carried out for time $\left(t_{a}\right)$ at temperature $\left(T_{a}\right)$.

dhe activated PHA reacts with HA for time $\left(t_{H A}\right)$ at the temperature $\left(T_{H A}\right)$.

${ }^{\mathrm{e}} \mathrm{GD}$ was determined by ${ }^{1} \mathrm{H}$ NMR spectroscopy; $\mathrm{nr}$ stands for non-reaction.

Compared to the literature data, the presented methodology is robust and economically feasible for synthesis of PHAs grafted to HA mediated by CDI-coupling agent. The main advantages of the presented methodology are: (i) possible coupling of two natural polymers, (ii) applicability on industrial scale mainly because of the mild reaction conditions and short activation time, (iii) usage of CDI coupling agent which is non-toxic, available at low price and stable for long term storage.

\subsection{Structural characterization of sodium hyaluronate graft-alkanoates}

The chemical structure of copolymers was characterized by a combination of analytical techniques NMR, FTIR and SEC-MALLS. NMR was also used for the determination of grafting degree, expressed in \% and defined as an average number of PHA chains attached to 100 disaccharide HA dimers. For example, grafting degree $=5.2 \%$ indicates that 5 out of 100 disaccharide HA dimers were modified (See Table 1, entry 8). grafting degree was determined using normalized integral intensity of ${ }^{1} \mathrm{H}$ NMR signals of the three $\mathrm{N}$-acetyl protons of $\mathrm{HA}$ located at $2.1 \mathrm{ppm}$ and signals of the terminal methyl group in PHA within the range of 1.2-1.8 ppm. A representative HSQC (heteronuclear single quantum coherence) spectrum of Oligo (3HB) grafted to HA is shown in Figure 4. This derivative will be used as an example to demonstrate the covalent bonding of $\mathrm{P}(3 \mathrm{HA})$ to $\mathrm{HA}$. The edited mode which allows the discrimination of $\mathrm{CH}_{3}$ and $\mathrm{CH}$ from $\mathrm{CH}_{2}$ groups in the structure was used to assign all the proton resonances in copolymers. Characteristic peaks of $\mathrm{HA}$ i.e., $\mathrm{N}$-acetyl group $\left(3 \mathrm{H},-\mathrm{COCH}_{3}\right)$, skeletal $(10 H, 2 a, 2 b, 3 a, 3 b, 4 a, 4 b, 5 a, 5 b$ and $6 a)$ and anomeric protons $(1 a, 1 b)$ of the HA chain appeared at $2.03,3.04-3.98$ and $4.46-4.55 \mathrm{ppm}$, respectively. Remaining signals detected in the spectrum of modified $\mathrm{HA}$ at $1.54\left(3 \mathrm{H}, \mathrm{d}-\mathrm{CH}_{3}\right), 3.04\left(2 \mathrm{H},-\mathrm{OCH}_{2}-\mathrm{C}=\mathrm{O}\right)$ and $5.12 \mathrm{ppm}(1 \mathrm{H},-\mathrm{CH}-)$ were attributed to 
Oligo (3HB) coupled to HA. Additionally, the ${ }^{1} \mathrm{H}$ NMR of oligo ((3HO-3HD-3HDD)-g-HA) is also included in Figure $\mathbf{S 4}$.

The formation of the linkage between alkanoates and HA was further confirmed by diffusion ordered NMR spectroscopy (DOSY). The DOSY map establishes diffusion of all proton signals in ${ }^{1} \mathrm{H}$ NMR spectrum. In case of covalent linkage between HA and alkanoates,

similar diffusion behaviour is expected to be observed for all signals (examples of oligo (3HB-g-HA and oligo (3HO-3HD-3HDD-g-HA are shown Figure 5 and S5). In contrast, the presence of free Oligo (3HB), which is only physically mixed with HA derivative, yields different diffusion pattern for the two entities. As it shown in Figures $\mathbf{5 6}$, signals corresponding to unbound Oligo (3HB) had faster diffusion compared to HA signals.

We also tried to confirm the formation of covalent bond between Oligo (3HB) and HA by IR spectroscopy. The characteristic IR spectrum of HA (Figure S7) shows absorptions at 3421, 2894, 1667, 1376, 1079,1038 and $611 \mathrm{~cm}^{-1}$ as reported in our previous work (Matelová et al., 2016). The IR spectrum Oligo (3HB) shows typical bands of methyl and methylenes in the region 2993, 2972 and $2930 \mathrm{~cm}^{-1}$. The asymmetric and symmetric $\mathrm{CH}_{3}$ stretching was also confirmed at 1465 and $1381 \mathrm{~cm}^{-1}$, respectively. Additionally, a sharp band located at $1724 \mathrm{~cm}^{1}$ was associated with $(\mathrm{O}-\mathrm{C}=\mathrm{O})$ stretching deformation (Domínguez-Díaz et al., 2015). Unfortunately, due to overlap of signals corresponding to the HA esterification (in substituted $\mathrm{HA}(\mathrm{GD} \geq 10 \%)$ ) and stretching deformation of $(\mathrm{O}-\mathrm{C}=\mathrm{O})$ in $\mathrm{PHA}$, the peak at $1725 \mathrm{~cm}^{-1}$ is not a clear indicative for covalent linkage between HA and PHA. It is worth to mention that the signal at $1272 \mathrm{~cm}^{-1}$ corresponding to the crystalline component of Oligo (3HB) (Domínguez-Díaz et al., 2015) vanished after conjugation with HA. In fact, unlike the pure P3HB component, the conjugate Oligo (3HB) grafted to HA displayed no crystallization when cooled from a melt state during the DSC non-isothermal crystallization run (Figure S8). 
The weight average molecular weight $(\mathrm{Mw})$ increased slightly as effect of the chemical modification (Table S2). Additionally, the polydispersity of the graft copolymers slightly increased in comparison with the parent HA but remained relatively low $(\leq 1.7)$.

\subsection{Cytocompatibility assay of hyaluronan graft-alkanoates}

The interaction of cells with modified HA derivatives is essential to be investigated for potential biomedical applications. After chemical modification of $\mathrm{HA}$, the produced derivatives should not be cytotoxic when incubated with healthy cells. The cytotoxicity was assessed by flow cytometry using direct contact assay (supplementary S5) using as a control untreated cells. Native HA used for the modification was found to be not cytotoxic (data not shown). Derivatives of entries 2, 6, 19 and 25 (Table 1) were assayed and found not to be cytotoxic up to concentration of $1,000 \mu \mathrm{g} \mathrm{mL}^{-1}$ (Figures 6 and Figures S9 and S10). Negligible effects and no significant differences in cell viability after 24 and $48 \mathrm{~h}$ were detected in the whole concentration range tested indicating a good cytocompatibility of the novel derivatives.

\subsection{Encapsulation of hydrophobic models.}

To demonstrate the potential application of the prepared derivatives, resveratrol and curcumin were used as hydrophobic model compounds for evaluation of encapsulation efficiency of (Oligo (3HB-g-HA)). Resveratrol is a hydrophobic but light sensitive compound, used for decreasing acne vulgaris signs (Fabbrocini et al., 2011). On the other hand, curcumin is a natural compound with antiinflammatory and anti-oxidant properties. However, limiting factors such as its extremely low oral bioavailability hampers its application as therapeutic agent (Liu et al., 2016). Both, resveratrol and curcumin were separately loaded in Oligo (3-hydroxybutyrate)-g-HA (grafting degree: 5.2 \%). Loading capacity was calculated and compared with previously reported results published by our group where different HA derivatives were used (Matelová et al., 2016; Nešporová et al., 2016). The loading capacity of curcumin in Oligo (3HB-g-HA) was more than 4 times larger compared with encapsulation by sodium oleyl hyaluronate (HA-C18:1), reported in our previous work (Nešporová et al., 2016). 
However, these two HA-based amphiphiles showed similar loading capacities for resveratrol. These results can be explained by differences between the compatibility of the nanomicellar core and the used model compound (Table 2). However, encapsulation is a very complex process and it is difficult to predict the drug-binding affinity of a novel carrier.

\section{Conclusions}

The synthesis of novel hydrophobized hyaluronan derivatives, containing oligomers of polyhydroxyalkanoates (Oligo PHA) was successfully achieved for the first time. The method described in this work allows the synthesis of a family of novel copolymers of well-defined structures, which are soluble in water. To extent the use of these materials in biomedical applications, grafting was envisioned through labile esters bonds to ensure in vivo biodegradability. The solvent was found to be determinant for the success of the coupling reaction. Although substitution reactions on HA by hydrophobic oligomers/polymers are challenging, in this study, CDI was confirmed to be an excellent acylation agent, which can be applied for conjugation of homopolymers of PHA characterized by short and medium chain length, as well as for copolymers of two or three of medium chain length. The chemical modification of HA by Oligomers of PHAs yielded a grafting degree up to $14 \%$. The main advantages of the proposed methodology are the mild reaction conditions and relatively short reaction time i.e. more than $98 \%$ conversion was reached after $4 \mathrm{~h}$. HA did not undergo any degradation. HA and oligo (3-hydroxyalkanoates) copolymers were successfully used to encapsulate hydrophobic drugs. In this study, we demonstrate the synthesis and characterization of set of novel biocompatible conjugates and take the first exploratory step towards application in drug delivery. The convenience of both biopolymers is opening a myriad of new applications.

\section{Acknowledgements}

This research has received funding from the European Community's Seventh Framework Programme (FP7-NMP-2013-SME-7) under grant agreement no 604450 (NEURIMP "Novel combination of biopolymers and manufacturing technologies for production of a peripheral nerve implant-containing 
an internal aligned channels array"). The authors gratefully thank to Lenka Hejlová, Pavlína Halamková and Jaroslav Novotný for the determination of SEC-MALLS, NMR and DSC, respectively (at CONTIPRO). PHAs production yield was improved by Barbara Lukasiewicz and Pooja Basnett (at UoW). Also, the authors would like to acknowledge their work.

\section{References}

Arslan, H., Hazer, B., \& Yoon, S. C. (2007). Grafting of poly (3-hydroxyalkanoate) and linoleic acid onto chitosan. Journal of applied polymer science, 103(1), 81-89.

Babinot, J., Guigner, J.-M., Renard, E., \& Langlois, V. (2012). Poly(3-hydroxyalkanoate)derived amphiphilic graft copolymers for the design of polymersomes. Chemical Communications, 48(43), 5364-5366.

Basnett, P., Ching, K. Y., Stolz, M., Knowles, J. C., Boccaccini, A. R., Smith, C., . . Roy, I. (2013). Novel Poly(3-hydroxyoctanoate)/Poly(3-hydroxybutyrate) blends for medical applications. Reactive and Functional Polymers, 73(10), 1340-1348.

Cappelli, A., Grisci, G., Paolino, M., Giuliani, G., Donati, A., Mendichi, R., . . . Vomero, S. (2014). Hyaluronan derivatives bearing variable densities of ferulic acid residues. Journal of Materials Chemistry B, 2(28), 4489-4499.

Chen, S.-C., Yang, M.-H., Chung, T.-W., Jhuang, T.-S., Yang, J.-D., Chen, K.-C., . . Tyan, Y.-C. (2017). Preparation and Characterization of Hyaluronic Acid-Polycaprolactone Copolymer Micelles for the Drug Delivery of Radioactive Iodine-131 Labeled Lipiodol. BioMed Research International, 2017, 4051763.

Chu, B., Shi, S., Li, X., Hu, L., Shi, L., Zhang, H., . . . Zhang, X. (2016). Preparation and evaluation of teniposide-loaded polymeric micelles for breast cancer therapy. International Journal of Pharmaceutics, 513(1-2), 118-129.

Cran, M. J., Gray, S. R., Scheirs, J., \& Bigger, S. W. (2011). Non-isothermal depolymerisation kinetics of poly(ethylene oxide). Polymer Degradation and Stability, 96(8), 1497-1502.

Domínguez-Díaz, M., Meneses-Acosta, A., Romo-Uribe, A., Peña, C., Segura, D., \& Espin, G. (2015). Thermo-mechanical properties, microstructure and biocompatibility in poly- $\beta$ hydroxybutyrates (PHB) produced by OP and OPN strains of Azotobacter vinelandii. European Polymer Journal, 63, 101-112.

El-Faham, A., \& Albericio, F. (2011). Peptide Coupling Reagents, More than a Letter Soup. Chemical Reviews, 111(11), 6557-6602.

Fabbrocini, G., Staibano, S., De Rosa, G., Battimiello, V., Fardella, N., Ilardi, G., . . Ayala, F. (2011). Resveratrol-Containing Gel for the Treatment of Acne Vulgaris. American Journal of Clinical Dermatology, 12(2), 133-141.

Heinze, T., Liebert, T., \& Koschella, A. (2006). Esters of Carboxylic Acids - Conventional Methods. In Esterification of Polysaccharides (pp. 41-52). Berlin, Heidelberg: Springer Berlin Heidelberg

Hsu, Y.-C., Wu, C.-S., Liao, H.-T., \& Cai, Y.-X. (2015). Improvement of the biocompatibility of polyhydroxyalkanoate by filling with hyaluronic acid. Journal of Materials Science, 50(23), 7790-7799.

Huerta-Angeles, G., Brandejsová, M., Kulhánek, J., Pavlík, V., Šmejkalová, D., Vágnerová, H., \& Velebný, V. (2016). Linolenic acid grafted hyaluronan: Process development, structural characterization, biological assessing, and stability studies. Carbohydrate Polymers, 152, 815-824. 
Li, J., Li, X., Ni, X., Wang, X., Li, H., \& Leong, K. W. (2006). Self-assembled supramolecular hydrogels formed by biodegradable PEO-PHB-PEO triblock copolymers and alphacyclodextrin for controlled drug delivery. Biomaterials, 27(22), 4132-4140.

Li, Z., \& Loh, X. J. (2015). Water soluble polyhydroxyalkanoates: future materials for therapeutic applications. Chemical Society Reviews, 44(10), 2865-2879.

Li, Z., Yang, J., \& Loh, X. J. (2016). Polyhydroxyalkanoates: opening doors for a sustainable future. NPG Asia Mater, 8, e265.

Liechty, W. B., Kryscio, D. R., Slaughter, B. V., \& Peppas, N. A. (2010). Polymers for Drug Delivery Systems. Annual review of chemical and biomolecular engineering, 1, 149173.

Liu, W., Zhai, Y., Heng, X., Che, F. Y., Chen, W., Sun, D., \& Zhai, G. (2016). Oral bioavailability of curcumin: problems and advancements. Journal of Drug Targeting, 24(8), 694-702.

Ma, Y.-M., Wei, D.-X., Yao, H., Wu, L.-P., \& Chen, G.-Q. (2016). Synthesis, Characterization and Application of Thermoresponsive Polyhydroxyalkanoate-graft-Poly $(\mathrm{N}$ isopropylacrylamide). Biomacromolecules, 17(8), 2680-2690.

Maitz, M. F. (2015). Applications of synthetic polymers in clinical medicine. Biosurface and Biotribology, 1(3), 161-176.

Martens, A. A., Besseling, N. A. M., Rueb, S., Sudhölter, E. J. R., Spaink, H. P., \& de Smet, L. C. P. M. (2011). Random Scission of Polymers: Numerical Simulations, and Experiments on Hyaluronan Hydrolosis. Macromolecules, 44(8), 2559-2567.

Matelová, A., Huerta-Angeles, G., Šmejkalová, D., Brůnová, Z., Dušek, J., Vícha, R., \& Velebný, V. (2016). Synthesis of novel amphiphilic hyaluronan containing-aromatic fatty acids for fabrication of polymeric micelles. Carbohydrate Polymers, 151, 11751183.

Mitragotri, S., Anderson, D. G., Chen, X., Chow, E. K., Ho, D., Kabanov, A. V., . . Xu, C. (2015). Accelerating the Translation of Nanomaterials in Biomedicine. ACS Nano, 9(7), 6644-6654.

Montalbetti, C. A. G. N., \& Falque, V. (2005). Amide bond formation and peptide coupling. Tetrahedron, 61(46), 10827-10852.

Nešporová, K., Šógorková, J., Šmejkalová, D., Kulhánek, J., Huerta-Angeles, G., Kubala, L., \& Velebný, V. (2016). Influence of serum albumin on intracellular delivery of drugloaded hyaluronan polymeric micelles. International Journal of Pharmaceutics, 511(1), 638-647.

Pravata, L., Braud, C., Boustta, M., El Ghzaoui, A., Toommeraas, K., Guillaumie, F., .. . Vert, M. (2007). New Amphiphilic Lactic Acid Oligomeric-Hyaluronan Conjugates: Synthesis and Physicochemical Characterization. Biomacromolecules, 9(1), 340-348.

Rai, R., Yunos, D. M., Boccaccini, A. R., Knowles, J. C., Barker, I. A., Howdle, S. M., . . . Roy, I. (2011). Poly-3-hydroxyoctanoate P(3HO), a Medium Chain Length Polyhydroxyalkanoate Homopolymer from Pseudomonas mendocina. Biomacromolecules, 12(6), 2126-2136.

Son, G. M., Kim, H. Y., Ryu, J. H., Chu, C. W., Kang, D. H., Park, S. B., \& Jeong, Y.-I. L. (2014). Self-Assembled Polymeric Micelles Based on Hyaluronic Acid-g-Poly(d,1lactide-co-glycolide) Copolymer for Tumor Targeting. International Journal of Molecular Sciences, 15(9), 16057-16068.

Staggs, J. E. J. (2002). Modelling random scission of linear polymers. Polymer Degradation and Stability, 76(1), 37-44.

Wei, L., McDonald, A. G., \& Stark, N. M. (2015). Grafting of Bacterial Polyhydroxybutyrate (PHB) onto Cellulose via In Situ Reactive Extrusion with Dicumyl Peroxide. Biomacromolecules, 16(3), 1040-1049. 
Zhou, L., Chen, Z., Chi, W., Yang, X., Wang, W., \& Zhang, B. (2012). Mono-methoxy-poly(3hydroxybutyrate-co-4-hydroxybutyrate)-graft-hyper-branched copolymers for siRNA delivery. Biomaterials, 33(7), 2334-2344.

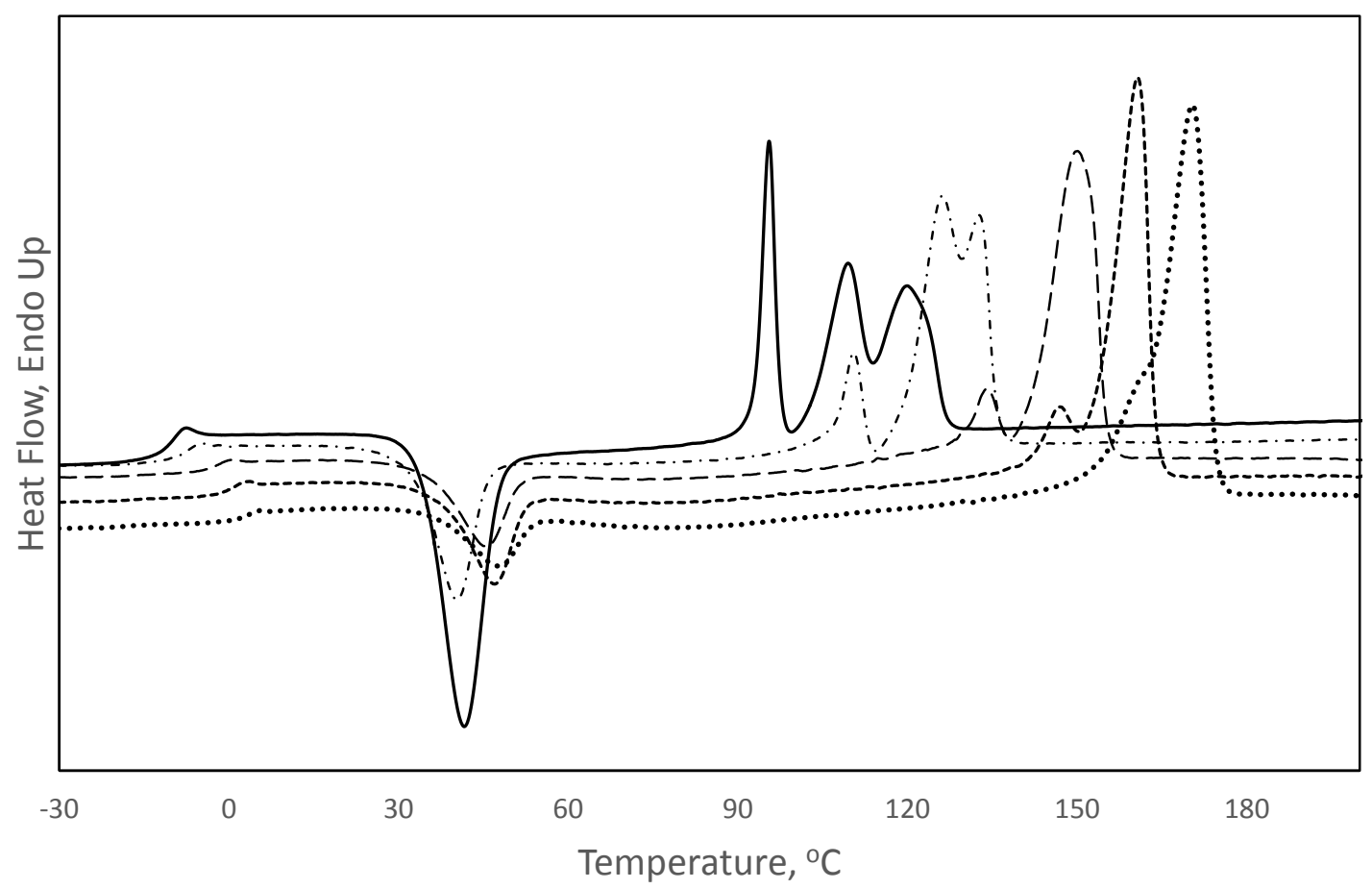

$<$ Inlinelmage3>

Figure 1. DSC thermograms depicts the initial $\mathrm{P}(3 \mathrm{HB})$ (dotted line) and hydrolysed for 3 (short dashed line), 8 (long dashed line), 20 (dot-dashed line) or 30 (solid line) hours, respectively. 
B

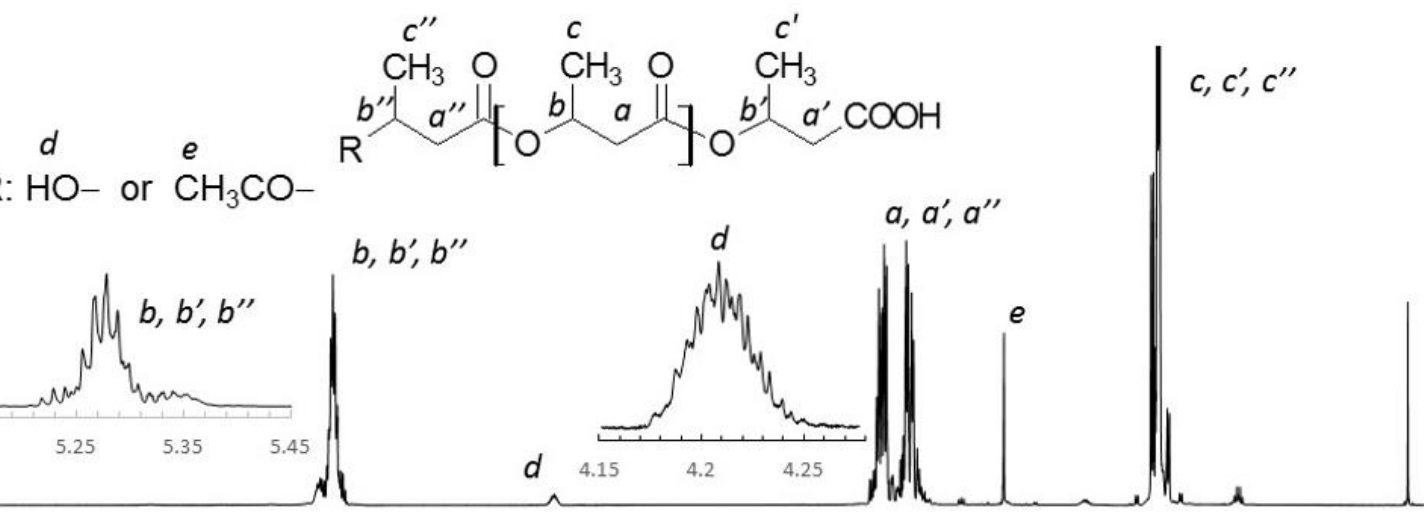

A

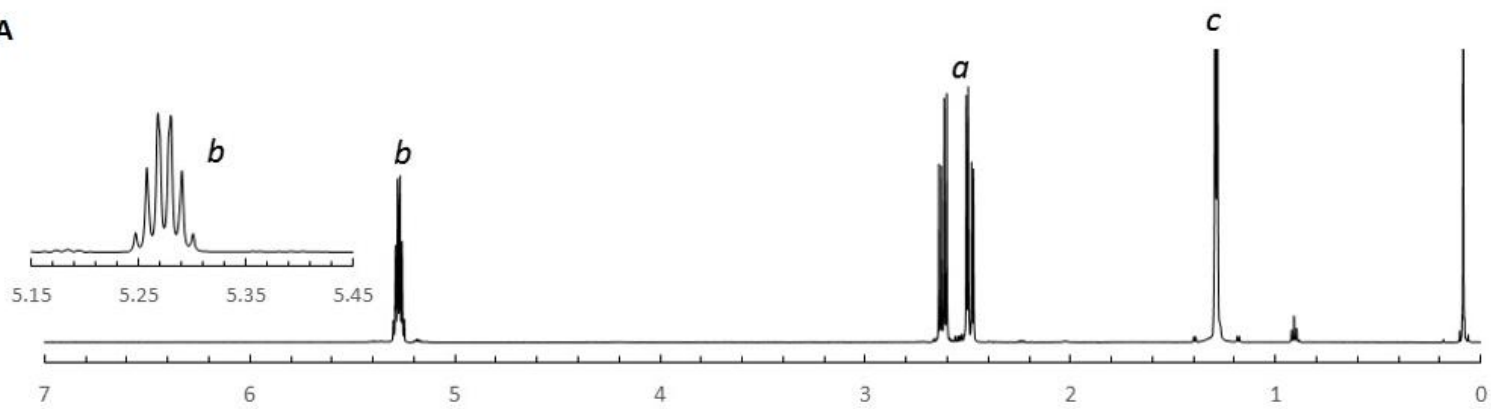

$<$ Inlinelmage4>

Figure 2. ${ }^{1} \mathrm{H}$ NMR spectra of $(\mathbf{A})$ initial $\mathrm{P}(3 \mathrm{HB})$ and $(\mathbf{B})$ Oligo(3HB) obtained for 30 hours of hydrolysis recorded in $\mathrm{CHCl}_{3}$

(A) Hydrolysis

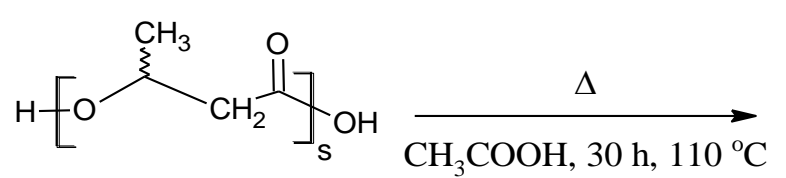<smiles>[R]C(C)CC(=O)OC(C)(C)CC(=O)OC(C)(C)C(C)CC(=O)O</smiles>

$\mathrm{R}=-\mathrm{OH}$ or $-\mathrm{OCOCH}_{3}$

<Inlinelmage5> 
(B) Activation

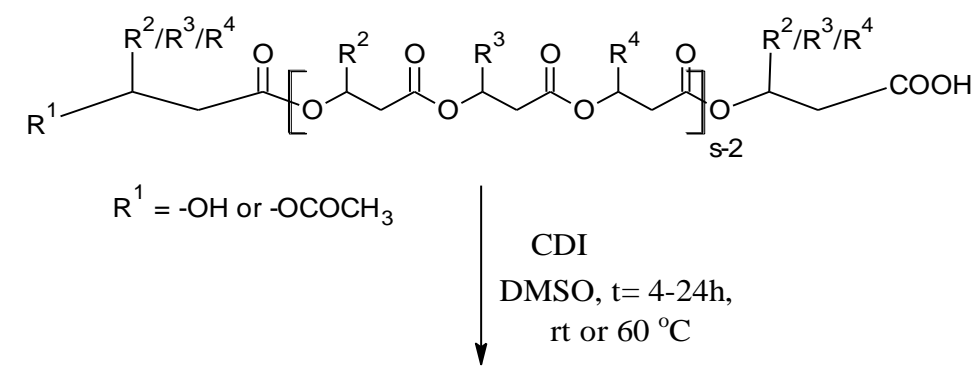

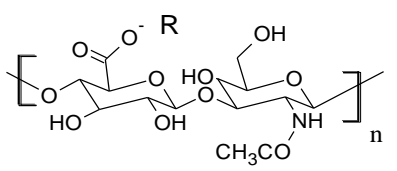

(C) Coupling

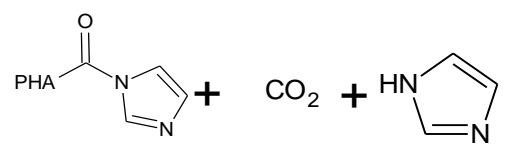

(1) PHA-CO-Im

TEA, DMAP in

$\mathrm{R}=\mathrm{TBA}^{+}, \mathrm{H}^{+}$or $\mathrm{Na}^{+}$

DMSO or DMSO/ $\mathrm{H}_{2} \mathrm{O}$

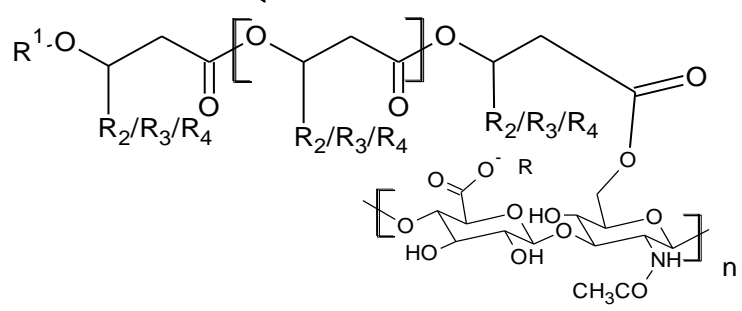

[Oligo (3HA) -graft -HA]
P3HB $\mathrm{R}^{2}=\mathrm{R}^{3}=\mathrm{R}^{4}=-\mathrm{CH}_{3}$
P(3HO -3HD)
$\mathrm{R}^{2}=-\left(\mathrm{CH}_{2}\right)_{4} \mathrm{CH}_{3}, \mathrm{R}^{3}=-\left(\mathrm{CH}_{2}\right)_{4} \mathrm{CH}_{3} \mathrm{R}^{4}=\mathrm{R}^{2}$ or $\mathrm{R}^{3}$
P3HO $R^{2}=R^{3}=R^{4}=-\left(\mathrm{CH}_{2}\right)_{4} \mathrm{CH}_{3}$
P(3HO-3HD -3HDD)
$\mathrm{R}_{2}=-\left(\mathrm{CH}_{2}\right)_{4} \mathrm{CH}_{3}, \mathrm{R}_{3}=-\left(\mathrm{CH}_{2}\right)_{6} \mathrm{CH}_{3} \mathrm{R}_{4}=-\left(\mathrm{CH}_{2}\right)_{8} \mathrm{CH}_{3}$
$<$ Inlinelmage6>

Figure 3. Chemical reactions involved in the synthesis of HA copolymers containing-PHAs (A) hydrolysis of $\mathrm{P}(3 \mathrm{HB})(\mathrm{B})$ Activation of the terminal carboxylic acid of PHA via imidazolide formation (PHACO-Im or 1) mediated by CDI and (C) coupling step with hyaluronan. 


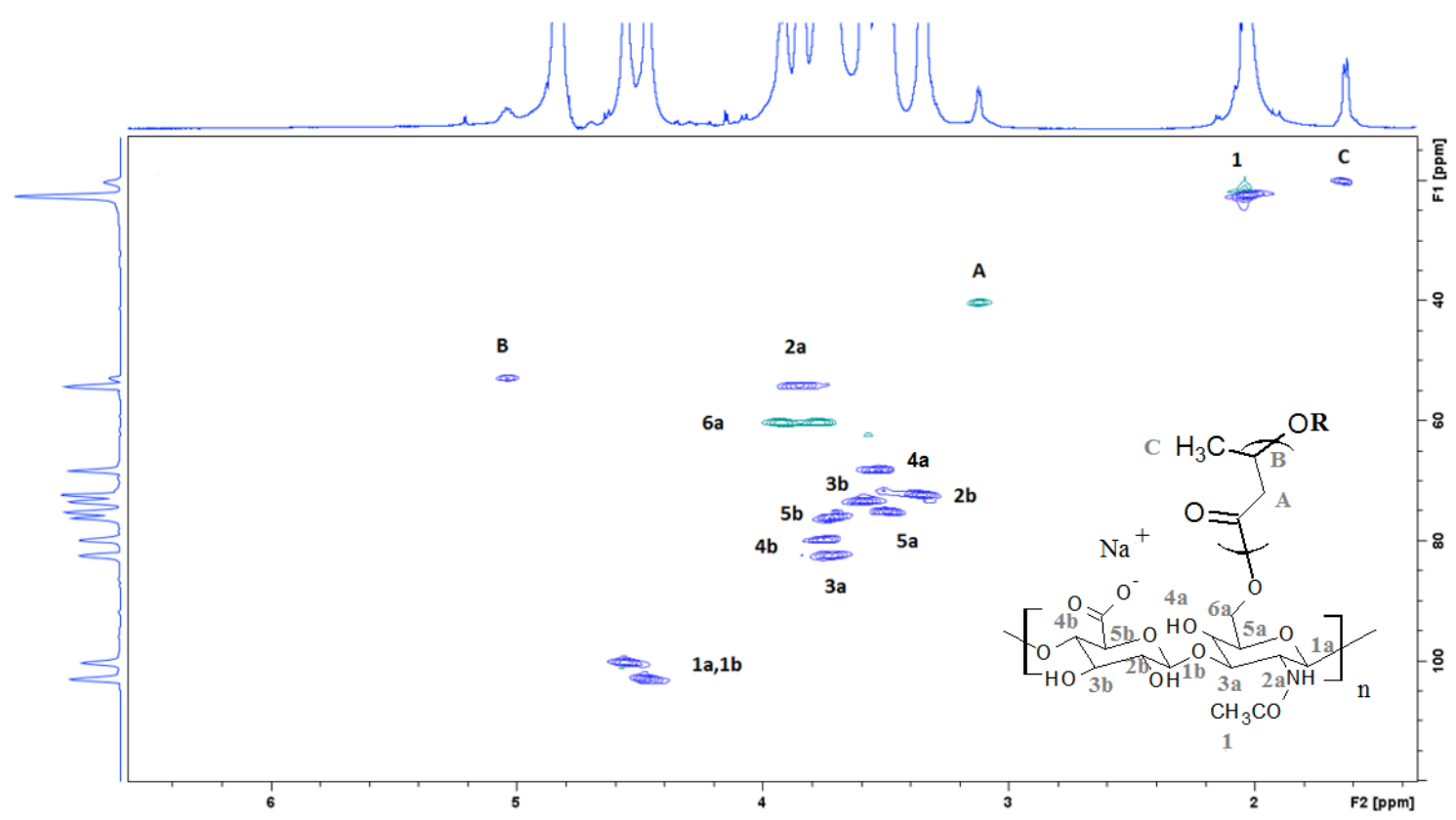

$<$ Inlinelmage7>

Figure 4. Edited Heteronuclear single quantum coherence (HSQC) spectrum corresponding to Oligo (3HB grafted $-\mathrm{HA}),\left(\mathrm{GD}=8.4 \%\right.$ and $\mathrm{Mw}=13,700 \mathrm{~g} / \mathrm{mol}$ ) recorded in $\mathrm{D}_{2} \mathrm{O}$.

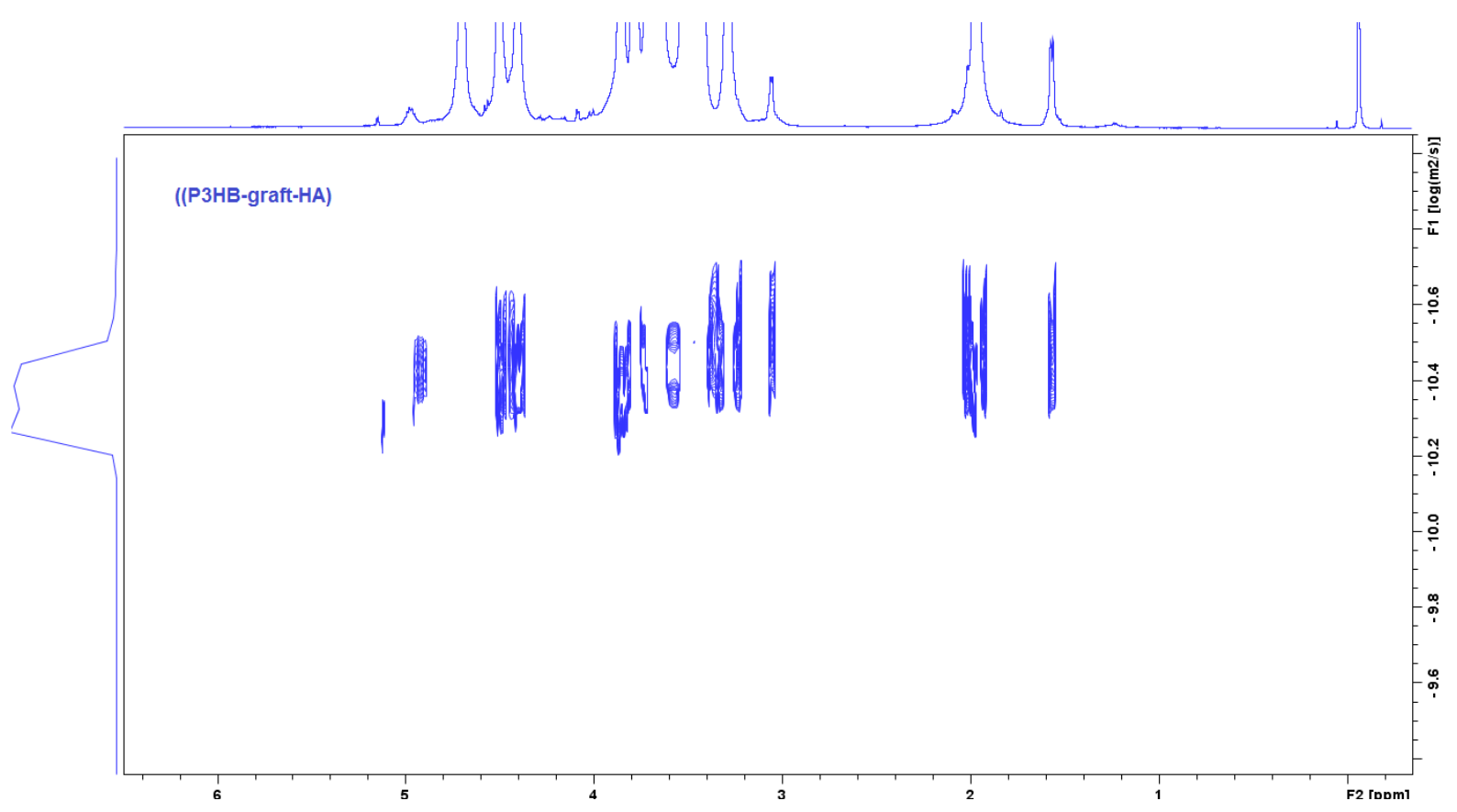

$<$ Inlinelmage8 $>$ 
Figure 5. DOSY NMR spectra of hyaluronan grafted with oligo 3-hydroxybutyrate (Oligo (3HB-g-HA)) recorded in $\mathrm{D}_{2} \mathrm{O}$ (Entry 22 , Table 1 ), $\mathrm{c}=12.5 \mathrm{mg} / \mathrm{ml}$ ).

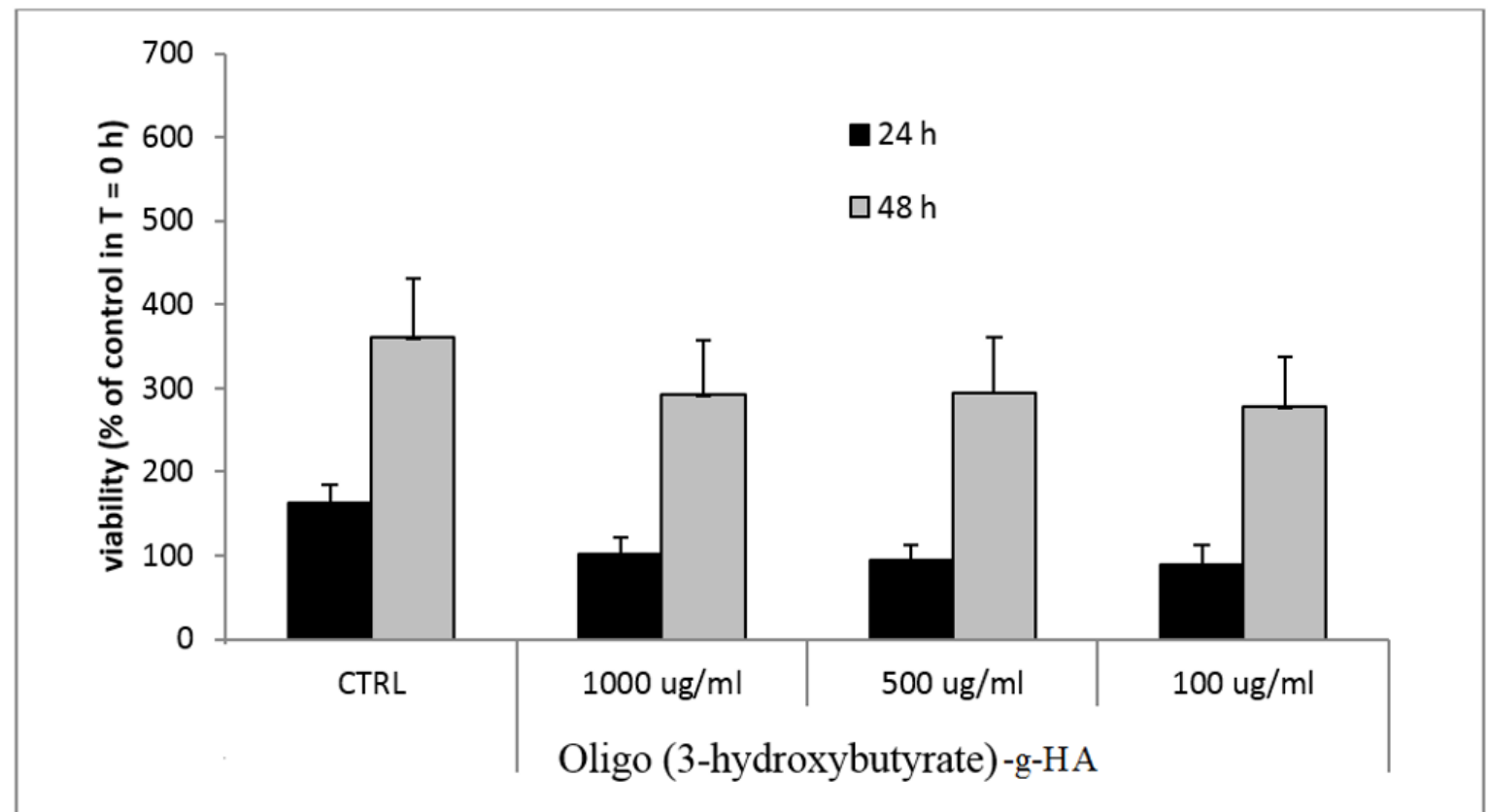

$<$ Inlinelmage9 $>$

Figure 6. Cell viability of Oligo (3-hydroxybutyrate)- grafted to sodium hyaluronate

Table 1. Reaction conditions for the synthesis of conjugates oligo (3HA-g-HA).

\begin{tabular}{|c|c|c|c|c|c|c|c|c|c|}
\hline Entry & Polymer ${ }^{\mathrm{a}}$ & $\begin{array}{l}\text { Coup. } \\
\text { agent }\end{array}$ & Solvent ${ }^{\mathrm{b}}$ & $\mathrm{t}_{\mathrm{a}(\mathrm{h})} \mathrm{c}$ & $\begin{array}{l}\mathrm{T}_{\mathrm{a}} \\
\left({ }^{\circ} \mathrm{C}\right)^{\mathrm{c}}\end{array}$ & $\begin{array}{l}\text { HA/PHA } \\
(\%)\end{array}$ & $\begin{array}{l}\mathrm{t}_{\mathrm{HA}} \\
(\mathrm{h})^{\mathrm{d}}\end{array}$ & $\begin{array}{l}\mathrm{T}_{\mathrm{HA}} \\
\left({ }^{\circ} \mathrm{C}\right){ }^{\mathrm{d}}\end{array}$ & $\begin{array}{l}\mathrm{GD}^{\mathrm{e}} \\
(\%)\end{array}$ \\
\hline \multicolumn{10}{|c|}{ HA (acid form) } \\
\hline 1 & Oligo $(3 \mathrm{HB})^{2}$ & CDI & DMSO & 4 & 60 & 100 & 12 & 25 & 2.5 \\
\hline 2 & \multirow[t]{2}{*}{ Oligo (3HO) } & CDI & DMSO & 4 & 60 & 100 & 12 & 60 & 4.1 \\
\hline 3 & & CDI & DMSO & 4 & 60 & 100 & 48 & 60 & 6.6 \\
\hline 4 & \multirow{3}{*}{$\begin{array}{l}\text { Oligo (3HO- } \\
\text { 3HD-3HDD) }\end{array}$} & CDI & DMSO & 4 & 60 & 100 & 12 & 60 & 2.6 \\
\hline 5 & & CDI & DMSO & 8 & 60 & 100 & 48 & 60 & 4.5 \\
\hline 6 & & CDI & DMSO & 4 & 60 & 100 & 48 & 60 & 5.3 \\
\hline \multicolumn{10}{|c|}{ HA-TBA } \\
\hline 7 & Oligo (3HO) & HSTU & DMSO & 8 & 60 & 100 & 48 & 60 & 0.8 \\
\hline 8 & $\begin{array}{c}\text { Oligo (3HO- } \\
\text { 3HD) }\end{array}$ & HSTU & DMSO & 8 & 60 & 100 & 48 & 60 & 0.9 \\
\hline 9 & \multirow{2}{*}{$\begin{array}{l}\text { Oligo (3HO- } \\
\text { 3HD-3HDD) }\end{array}$} & HSTU & DMSO & 8 & 60 & 100 & 48 & 60 & 1.4 \\
\hline 10 & & CDI & DMSO & 8 & 60 & 100 & 48 & 60 & 2.4 \\
\hline
\end{tabular}




\begin{tabular}{|c|c|c|c|c|c|c|c|c|c|}
\hline 11 & \multirow[t]{2}{*}{$\mathrm{P}(3 \mathrm{HB})^{1}$} & CDI & $\mathrm{DMSO} / \mathrm{H}_{2} \mathrm{O}$ & 4 & 60 & 100 & 12 & 60 & 0.4 \\
\hline 12 & & CDI & $\mathrm{DMSO} / \mathrm{H}_{2} \mathrm{O}$ & 24 & 25 & 100 & 24 & 25 & 0.5 \\
\hline 13 & \multirow{10}{*}{ Oligo $(3 \mathrm{HB})^{2}$} & $\mathrm{BC}$ & $\mathrm{DMSO} / \mathrm{H}_{2} \mathrm{O}$ & 2 & 25 & 100 & 12 & 25 & $n r$ \\
\hline 14 & & $\mathrm{BC}$ & THF & 2 & 25 & 100 & 12 & 25 & $n r$ \\
\hline 15 & & TBC & $\mathrm{DMSO} / \mathrm{H}_{2} \mathrm{O}$ & 2 & 25 & 100 & 12 & 25 & $n r$ \\
\hline 16 & & CDI & formamide & 2 & 25 & 100 & 12 & 25 & $n r$ \\
\hline 17 & & CDI & $\mathrm{DMSO} / \mathrm{H}_{2} \mathrm{O}$ & 4 & 60 & 100 & 12 & 25 & 2.1 \\
\hline 18 & & CDI & DMSO/H2O & 4 & 25 & 50 & 12 & 25 & 0.1 \\
\hline 19 & & CDI & $\mathrm{DMSO} / \mathrm{H}_{2} \mathrm{O}$ & 4 & 25 & 100 & 12 & 25 & 5.2 \\
\hline 20 & & CDI & $\mathrm{DMSO} / \mathrm{H}_{2} \mathrm{O}$ & 4 & 25 & 150 & 24 & 25 & 7.1 \\
\hline 21 & & CDI & $\mathrm{DMSO} / \mathrm{H}_{2} \mathrm{O}$ & 4 & 25 & 200 & 24 & 25 & 8.4 \\
\hline 22 & & CDI & $\mathrm{DMSO} / \mathrm{H}_{2} \mathrm{O}$ & 24 & 25 & 200 & 24 & 25 & 13.8 \\
\hline 23 & \multirow[t]{2}{*}{ Oligo (3HO) } & CDI & $\mathrm{DMSO} / \mathrm{H}_{2} \mathrm{O}$ & 4 & 60 & 100 & 12 & 25 & 1.2 \\
\hline 24 & & CDI & $\mathrm{DMSO} / \mathrm{H}_{2} \mathrm{O}$ & 4 & 60 & 100 & 12 & 60 & 0.8 \\
\hline 25 & \multirow[t]{2}{*}{$\begin{array}{c}\text { Oligo (3HO- } \\
\text { 3HD) }\end{array}$} & CDI & $\mathrm{DMSO} / \mathrm{H}_{2} \mathrm{O}$ & 4 & 60 & 100 & 12 & 25 & 1.5 \\
\hline 26 & & CDI & $\mathrm{DMSO} / \mathrm{H}_{2} \mathrm{O}$ & 4 & 60 & 100 & 12 & 60 & 0.9 \\
\hline 27 & \multirow{2}{*}{$\begin{array}{l}\text { Oligo (3HO- } \\
\text { 3HD-3HDD) }\end{array}$} & CDI & $\mathrm{DMSO} / \mathrm{H}_{2} \mathrm{O}$ & 4 & 60 & 100 & 12 & 25 & 0.6 \\
\hline 28 & & CDI & $\mathrm{DMSO} / \mathrm{H}_{2} \mathrm{O}$ & 4 & 60 & 100 & 12 & 60 & 0.3 \\
\hline
\end{tabular}

Table 2. Loading capacity of derivatives Oligo (3HB-g-HA) and HA-C18:1 evaluated for curcumin and resveratrol.

\begin{tabular}{|c|c|c|c|c|}
\hline \multicolumn{5}{|c|}{ Resveratrol } \\
\hline $\begin{array}{c}\text { (Oligo (3HB-g-HA)) } \\
(\mathrm{mg} / \mathrm{mg})\end{array}$ & solvent & $\begin{array}{c}\text { Loading } \\
\text { capacity } \\
\text { (wt. \%) }\end{array}$ & $\begin{array}{c}\text { HA-C18:1 } \\
(\mathrm{mg} / \mathrm{mg})\end{array}$ & $\begin{array}{c}\text { Loading } \\
\text { capacity } \\
\text { (wt. \%) }\end{array}$ \\
\hline 100:5 & IPA & 0.8 & $100: 5$ & 1.3 \\
\hline \multicolumn{5}{|c|}{ Curcumin } \\
\hline $\begin{array}{c}\text { (Oligo (3HB-g-HA)) } \\
(\mathrm{mg} / \mathrm{mg})\end{array}$ & solvent & $\begin{array}{c}\text { Loading } \\
\text { capacity } \\
\text { (wt. \%) }\end{array}$ & $\begin{array}{c}\text { HA-C18:1 } \\
(\mathrm{mg} / \mathrm{mg})\end{array}$ & $\begin{array}{c}\text { Loading } \\
\text { capacity } \\
\text { (wt. \%) }\end{array}$ \\
\hline 100:5 & IPA & 3.3 & $100: 5$ & 0.7 \\
\hline
\end{tabular}

